\title{
A HOMOAFETIVIDADE FEMININA EM LYGIA FAGUNDES TELLES
}

Carlos Magno Gomes (UFS)

Resumo: Este ensaio apresenta um estudo sobre a identidade sexual homoerótica na ficção de Lygia Fagundes Telles em seu primeiro romance, Ciranda de pedra (1954), e no conto "Uma branca sombra pálida", da coletânea A noite escura mais eu (1995). Respectivamente, essas narrativas questionam o conservadorismo da sociedade brasileira por meio da exploração do homoerotismo feminino como transgressão identitária. Metodologicamente, exploramos conceitos de identidade propostos por Judith Butler e Guacira Louro. Essas teóricas dialogam quanto ao fato de essa identidade ser vista como uma forma de oposição e resistência ao padronizado.

Palavras-chave: homoerotismo feminino, romance de formação, identidade.

Abstract: This paper presents a comparative study between the homo-affective space in the works Ciranda de pedra (1954) and "Uma branca sombra pálida" (1995), by Lygia Fagundes Telles. When describing female homo-affective relations, this author question the conservative moral of the Brazilian societie. Methodologically, we explore concepts of homosexual identity, proposed by Judith Butler and Guacira Louro, who emphasize that sexual identity as a form of feminine opposition and resistance.

Keywords: female homoeroticism, apprenticeship novel, identity.

Na Literatura Brasileira, a homoafetividade feminina possui um discreto lugar, pois, quase sempre, fica restrita a estereótipos que aprisionam mulheres a imagens masculinizadas ou a seres assexuados. Essas marcas são comuns a personagens andróginos, que transitam entre os comportamentos masculino e feminino e são vistos como 
excêntricos como nos contos “O corpo" (1973), de Clarice Lispector, "Tigrela" (1977), de Lygia Fagundes Telles, ou nos romances As parceiras (1980), de Lya Luft, e Vozes do deserto (2004), de Nélida Piñon. Essas representações rejeitam a premissa da solidez da identidade que, por ser uma categoria negociável e renovável, passa por decisões, caminhos percorridos, maneiras de agir, e dificilmente se mantêm firme a um centro, visto que o pertencimento identitário é flexível (BAUMAN, 2005, p. 17).

Nessas narrativas, a homoafetividade entre mulheres, a troca de afeto e carícias, vai além de um comportamento exótico, pois questiona a identidade heterossexual como um padrão fixo. Mesmo assim, a crítica literária ainda trata essa representação pelo paradigma da invisibilidade ou do "não-ser". Portanto, precisamos seguir uma proposta de intervenção crítica capaz de resgatar a homossexualidade feminina do espaço marginalizado da literatura brasileira (BAILEY, 2004, p. 02). Partindo dessa proposta, analisamos a representação da homossexualidade como uma forma de contestação das normas impostas e ressaltamos a provisoriedade dessa identidade nos textos ficcionais.

Nos textos citados acima, a homafetividade feminina não está relacionada a uma vida sexual ativa, mas à amizade 
e à parceria que passam a ser usadas como formas de resistência contra a opressão heterossexual. Em oposição a esse padrão uniforme, as personagens dessas narrativas transitam pelo território da sexualidade homoafetiva, sem perder o vínculo com a sociedade que as cerca. Tal representação foge dos paradigmas "que tanto procuram controlar a sexualidade feminina, como restringir o acesso da mulher a uma linguagem adequada à representação de sua sexualidade" (BAILEY, 2004, p. 02)

Particularmente, na fição de Lygia Fagundes Telles, temos diversos exemplos desses amores platônicos e ambíguos entre mulheres como a delicada relação de Lia com uma amiga em sua juventude em As meninas (1973). Para este ensaio, vamos fazer um recorte das personagens femininas que apresentam um comportamento homoafetivo em Ciranda de Pedra (1954) e em "Uma branca sombra pálida", da coletânea A noite escura mais eu (1995). Ao descrever personagens femininas com comportamento sexual ambíguo, a autora propõe uma abordagem crítica dessa identidade sexual. Essa representação debate as fronteiras da sexualidade feminina, questionando a opressão e o preconceito contra o amor entre duas mulheres dentro de uma concepção existencial marcada pela heterossexualidade. 
Metodologicamente, exploramos o conceito de identidade sexual e de gênero proposto por Judith Butler, que defende a flexibilidade e a performance corporal como parte do processo contínuo da construção identitária "no e através do outro" (2003, p. 205). Nessa mesma linha de raciocínio, Guacira Louro reforça a premissa de que a identidade sexual é flexível e é parte dos conflitos sociais (2008, p. 27). Nesse sentido, fazemos um recorte teórico do conceito de identidade homossexual para evitar a complexidade e abrangência desse termo. Optamos pela definição de Guacira Louro que reconhece essa identidade pela escolha do par amoroso, pois "a identidade gay ou lésbica assenta-se na preferência em manter relações sexuais com alguém do mesmo sexo" (2008, p. 33). Outro aspecto teórico importante da ambiguidade sexual é o fato de a representação da homossexualidade estar associada à "ausência de fronteira entre a sexualidade masculina e a feminina" (TOURAINE, 2007, p. 68). Tais particularidades estão presentes na narrativa de Lygia Fagundes Telles.

Os ruídos provocados por essa representação são fundamentais para entendermos de que forma 0 preconceito e o estigma se repetem nos dois momentos. Essa representação é polêmica por ir contra os "bons 
costumes" e ser vista como espaço alternativo para a identidade sexual transgressora. Diante de uma sociedade castradora, Lygia Fagundes Telles apresenta o espaço homoerótico feminino em contraposição ao social, isto é, um espaço de contestação.

Nesse imaginário literário, a homoafetividade é descrita por meio de uma heterotopia de desvio, visto que a mulher abandona, mesmo que provisoriamente, a opção normatizada, para experimentar uma viagem erótica pelo corpo da amada. Em Ciranda de Pedra, temos a personagem Letícia, que após uma decepção amorosa com um homem, passa a se interessar afetivamente por meninas. Em "Uma branca sombra pálida", o amor entre duas jovens ultrapassa a barreira da amizade e torna-se um pesadelo para uma mãe castradora. Tais opções trazem duas formas de representação do homoerotismo feminismo que tanto pode ser vista como um processo de desilusão feminina com o parceiro heterossexual, como também parte do processo de formação sexual de uma mulher (BAILEY, 2004, p. 10).

A opção estética que contesta as representações tradicionais traz para o texto literário o debate social dos significados morais e artísticos dessa identidade. Nesses casos, o homoerotismo configura-se por meio da 
performance corporal do sujeito feminino que se desloca em busca da liberdade e do seu corpo e da amada. Portanto, o deslocamento da identidade feminina é fundamental, visto que há um processo de aprendizado sexual que vai além do contato físico, pois corresponde a "novas formas" de vermos o mundo (LOURO, 2008, p. 15). Além do mais, essa instabilidade pode ser vista como uma possibilidade de desconstrução sexual, visto que devemos levar em conta que há "a possibilidade de colocar a consolidação das normas do sexo em uma crise potencialmente produtiva" (BUTLER, 2001, p. 164).

Ao descrever que uma personagem feminina opta pelo carinho de outra mulher, o texto nos sugere que algo está sempre sendo adiado no processo de construção da identidade sexual, visto que essa flexibilidade reforça a premissa de que a identidade de gênero não é apenas o resultado determinado pelas regras impostas, "porque é antes um processo regulado de repetição que tanto se oculta quanto impõe suas regras, precisamente por meio da produção de efeitos substancializantes" (BUTLER, 2003, p. 209). Para melhor exemplificar essas considerações iniciais, passemos a comentar as particularidades dessa representação na ficção de Lygia Fagundes Telles. 
Em Ciranda de pedra, essa autora quebra o paradigma social da heterossexualidade ao colocar a experiência homoafetiva como parte do processo de formação da jovem Virgínia, que, após anos de internato, volta para viver com sua família, o pai, Natércio, e suas irmãs, Bruna e Otávia, e reencontrar os amigos de infância, Conrado, Letícia e Afonso. Após o reconhecimento do jogo de interesses de familiares e amigos, Virgínia se mostra descontente com todos e resolve abandonar aquela ciranda de aparências.

O pioneirismo dessa obra está na exploração da homoafetividade feminina como uma opção sexual para a jovem em formação, Virgínia. Essa marca também pode ser vista pela forma como a autora aborda tal tema sem aprisionar a mulher a uma sexualidade fixa, nem determinar o caráter dessa representação, vinculando-a a questões de caráter e a de certas profissões como pregam os estereótipos culturais (TOURAINE, 2007, p. 67).

No contexto da formação educacional da jovem transgressora, Virgínia, o amor entre mulheres era visto como um confronto com a tradição, por isso a passagem por essa experiência sexual reforça seu lugar como um espaço de resistência. Diversas vezes, Virgínia testa seu pertencimento identitário quando se envolve com Afonso, o cunhado, 
e quando se sente rejeitada por Conrado, um namorado platônico de infância. Diante desses episódios de decepção com a afetividade masculina, ela se sente desprotegida e vulnerável, por isso passa a aceitar os convites de Letícia para fazer traduções e visitar seu apartamento.

Ao se mostrar descontente com o jogo sexual dos homens à sua volta, sem alternativa, Virgínia se deixa levar pela sedução da amiga, mesmo quando tem consciência que vai ser usada por ela. Dessa forma, Ciranda de pedra reforça a premissa de que a identidade nem sempre é coerente e consistente, porque necessita de diferentes interseções com diversas identidades (BUTLER, 2003, p. 20). O fato de Virgínia aceitar o jogo de sedução feminino reforça sua necessidade de experimentar outros pertencimentos identitários.

Com isso, a capacidade crítica desse romance está na exploração da homoafetividade feminina como uma possibilidade identitária para a mulher transgressora e como um pesadelo para a identidade legitimadora (BAUMAN, 2005, p. 38). Os deslocamentos sexuais que sustentam o interesse de Letícia por Virgínia são atravessados por questões sexuais e sociais. Apesar de ser solidária e receptiva com Virgínia, Letícia, desde o início, tenta conquistá-la por meio de um assédio sexual visível a 
todos. Com a insistência de Letícia, a relação entre amigas vai ganhando dimensões homoafetivas, que compreende da sedução inicial ao beijo forçado. A performance sexual de Letícia merece destaque, pois apresenta uma identidade sexual sempre em transformação. Ela teve diversas relações heterossexuais no passado. No presente, quando se sente atraída por uma mulher, parte para conquistá-la, mostrando-se livre das concepções sexuais impostas.

Por ser uma atleta, Letícia apresenta um perfil andrógino que misturam características femininas e masculinas: é "magra mas musculosa" (TELLES, 1998, p. 102). Esse corpo masculinizado dá indícios da construção identitária fora das normas ditas "femininas". A partir dessa performance corporal, a identidade sexual vai sendo lapidada, uma vez que seu pertencimento sexual fica exposto e aberto a outras possibilidades, revelando autocríticas e performances de seu pertencimento identitário (BUTLER, 2003, p. 211).

Por não ter um pertencimento identitário padronizado, Letícia é uma personagem em trânsito que recusa a limitação das fronteiras corporais. Ela assume socialmente um pertencimento em movimentoquesemanifestana inconstância e na transição das identidades (LOURO, 2008, p. 22). Ela não só apresenta um tipo físico fora dos padrões femininos 
tradicionais, como também opta por comportamentos que contestam os valores familiares burgueses.

No processo de aproximação das duas, o apartamento de Letícia é usado como espaço de refúgio, no qual o jogo de sedução vai se ampliando. Nesse sentido, o apartamento pode ser visto como local de resistência para essa relação ambígua, que envolve sedução e desejo. Esse espaço fora do controle da família é o local da transgressão. Por ser um lugar elitizado, ele é também marcado pela questão de classe e reforça certa invisibilidade para o lesbianismo, que era visto por alguns setores da sociedade como uma experiência sexual de classes altas, pois estava associado a uma prática decadente ou fascinante e própria da elite brasileira (BAILEY, 2004, p. 10).

Mesmo com a confirmação de que estava sendo seduzida por Letícia, Virgínia não se afasta dela, pelo contrário passa a jogar com aquela situação, e reconhece que "isso lhe daria náuseas", no entanto, agora não sentia “nem náuseas nem espanto" (TELLES, 1998, p. 139). Nesse processo consciente de que está transitando por territórios sexuais desconhecidos, essa protagonista assume o risco de se envolver com outra mulher. Por meio de um ato performativo, ela rearticula sua identidade quando executa 
uma "prática discursiva" que a nomeia de outro lugar (BUTLER, 2001, p. 167).

Depois de muita insistência, Letícia consegue seduzi-la. No entanto, como a experiência é desagradável, Virgínia retoma suas referências identitárias, passando a se projetar sendo beijada por um homem, mostrando o quanto está apenas testando seus limites sexuais: "Entregou-se passiva ao beijo demorado. Fechou os olhos. Conrado, Conrado" (TELLES, 1998, p. 144). Com isso, essa obra tem a peculiaridade de destacar uma protagonista que testa sua identidade sexual para além das normas que lhe foram impostas, ao se deixar seduzir por outra mulher.

Ao fazer referência ao carinho heterossexual, Virgínia tenta desesperadamente voltar para o seu lugar cômodo e se agarra às normas que conhece para fugir das carícias da amiga. Nesse caso, ela opta por citar o discurso que já conhece, visto que "a norma do sexo assume o controle na medida em que ela é citada como tal norma, mas ela também deriva seu poder através das citações que ela impõe" (BUTLER, 2001, p. 168).

Embora não se sinta bem, recebendo as primeiras carícias e beijos de outra mulher, Virgínia continua naquele jogo erótico a fim de testar seu pertencimento e seus limites: "sentiu a boca de Letícia roçar-lhe pelo pescoço e subir lenta 
até alcançar-lhe os lábios" (TELLES, 1998, p. 144). Dessa experiência, podemos destacar que, embora não se mostre contente, Virgínia passou pelo processo de pertencimento homoafetivo de forma consciente, pois testou seus limites e expôs regras que não conhecia como sua preferência afetiva pela carícia de Conrado. Se, por um lado, Virgínia não se identifica com aquela opção; por outro, Letícia reforça o quanto domina aquelas técnicas de conquista feminina.

Assim, entre a tensão sexual que há entre as duas, o processo do pertencimento sexual é testado, abrindo espaço para a homoafetividade como uma das opções possíveis, visto que a identidade sexual transgressora se projeta como parte daquele contexto por meio de um processo regulado de repetição que "tanto se oculta quanto impõe suas regras, precisamente por meio da produção de efeitos substancializantes" (BUTLER, 2003, p. 209). Sem corresponder aos desejos de Letícia, Virgínia opta por não dar continuidade aos carinhos da amiga. Ao ratificar seu pertencimento heterossexual, percebemos que "há diferenças a serem atenuadas ou desculpadas ou, pelo contrário, ressaltadas e tornadas mais claras" (BAUMAN, 2005, p. 19).

Dessa forma, ao fazer o questionamento das fronteiras sexuais, Ciranda de pedra atualiza o debate sobre essa representação e resgata o tema a partir de uma experiência 
concreta na qual está em jogo a identificação com essa sexualidade. Grosso modo, os interesses das duas ressaltam que se trata de uma relação correspondida, mesmo que com interesses diferentes. Letícia com a finalidade de seduzir mais uma namorada; Virgínia em busca de outros espaços para sua identidade. Nessa interseção, a representação do homoerotismo feminino se projeta como um lugar de questionamento e revisão das identidades tradicionais. Além disso, há um diferencial nessa representação, visto que Letícia, mesmo pertencendo a uma zona rejeitada socialmente, reivindica sua autonomia à vida, pois sua identidade "é constituída através da força da exclusão e da abjeção" (BUTLER, 2001, p. 155).

Essa temática é retomada por Lygia Fagundes Telles 40 anos depois em "Uma branca sombra pálida". Bem diferente da primeira abordagem, esse conto aborda o tema pelo prisma da mãe culpada pelo suicídio da filha. Nesse caso, a identidade homoerótica é vista como um corpo abjeto, um corpo que pesa para a família tradicional. Com isso, a ficção faz uma reflexão crítica ao questionar a formação do sujeito homoerótico por meio da normatização do sexo como um padrão cultural. Esse processo pode ser identificado por meio de um repúdio que produz a abjeção e reconhece 
na identidade transgressora um "espectro ameaçador" (BUTLER, 2001, p. 156).

Esse espectro assombra duplamente a mãe diante do túmulo da filha e de suas recordações do suicídio. Sem se conformar com a perda da filha, a mãe busca explicações para a tragédia que foi antecedida da relação homoafetiva entre sua filha, Gina, e Oriana. Ao optar por uma ruptura com o espaço tradicional da mãe, Gina também ressalta sua rejeição ao padrão fixo da heterossexualidade. A narrativa retoma os episódios dessa crise de identidade a partir do entrecruzamento entre a cena no cemitério e as cenas homoafetivas da filha. Nesse espaço do cemitério, a mãe tradicional relembra, de forma sádica, cada um dos episódios que levaram sua pequena Gina ao suicídio.

Ao optar por uma narrativa fatal, Lygia Fagundes Telles destaca o choque entre a identidade homoafetiva em oposição à postura castradora da mãe. Nesse caso, o espaço do cemitério é muito importante para entendermos o que está em jogo nessa representação, pois temos tanto o silenciamento da homossexual, como os fantasmas do passado da mãe opressora. Nesse caso, o cemitério aponta os espaços heterogêneos da mãe, no qual ela é sulcada e corroída pelas "categorias de sexo", pois será assombrada 
"pelas próprias instabilidades que as categorias efetivamente produzem e integram" (BUTLER, 2001, p. 156).

No processo de deslocamento pelo passado, a mãe reconhece que a filha "parecia tão feliz lá no seu quarto todo branco" e destaca o quanto a amizade das duas lhe incomodava, pois "falavam e ouviam música e riam" (TELLES, 1998, p. 132). Nessas viagens pessoais, que as duas faziam trancadas no quarto, Gina se aproxima de si, pois “a viagem transforma o corpo, o 'caráter', a identidade, o modo de ser e de estar" (LOURO, 2008, p. 15). Por meio desses encontros, Gina experimenta novas posições de gênero e de sexo. Sua aprendizagem se consolida por meio dessas viagens trancadas em seu quarto.

No cemitério, mesmo sendo um lugar de encontros e desencontros, a mãe não consegue se livrar do seu olhar castrador, pois não aceita que a namorada da filha lhe traga flores vermelhas: "Depois veio o sol e as vermelhonas se fartaram de calor, obscenas de tão abertas" (TELLES, 1998, p. 128). As referências irônicas à cor vermelha apontam a posição castradora da mãe e sua forma conservadora de avaliar o desenrolar da relação entre a filha e Oriana.

Nesse processo, temos pontos de partidas e chegadas dessas duas identidades. Mãe e filha vivem encontros e 
desencontros por meio da heterotopia do cemitério. Desses desencontros, destaca-se a forma como as duas viajam por universos opostos da sexualidade. Essa oposição fica ressaltada pela fala disciplinadora e excludente da mãe ao se referir à amizade afetiva das duas: "Ah, que coincidência, porque também eu não me conformo, a diferença apenas é que você gosta de fazer sujeira, Você é suja!" (TELLES, 1998, p. 128). Ao rejeitar o relacionamento homoafetivo de Gina, a mãe tenta de toda forma controlar a sexualidade da filha.

Sem aceitar os encontros de Gina com Oriana, a mãe se mantém presa a um referencial afetivo fixo e limitador, mesmo quando avalia suas imposições: "mas não seria mais lógico cada qual cumprindo até o infinito o ofício da paixão?" (TELLES, 1998, p. 130). Esse conflito materno deixa uma brecha para interpretarmos que nem ela mesma acreditava naquilo que questionava na filha, visto que não existe um "eu" ou um "nós" que não tenha sido submetido à identidade de gênero e subjetivado por ela, posto que o processo de identificação emerge no interior das próprias relações de gênero e como matriz dessas relações (BUTLER, 2001, p. 159).

Sem espaço para concretizar sua performance de gênero, Gina parte para um deslocamento fatal. Ela escolhe o 
domingo de Páscoa para fugir da opressão da mãe que Ihe impunha como única opção a identidade homogênea: "Levantei a voz, mas falei devagar. A escolha é sua, Gina. Ou ela ou eu, você vai saber escolher, não vai? Ou fica com ela ou fica comigo, repeti e fui saindo sem pressa" (TELLES, 1998, p. 137). Ao nomear a única opção para a filha, a mãe decretava sua verdade, pois "a nomeação é, ao mesmo tempo, o estabelecimento de uma fronteira e também a incultação repetida de uma norma" (BUTLER, 2001, p. 161).

Depois de ter imposto um fim para a relação das duas, a mãe se mostra aliviada, pois tinha cumprido seu papel de normatizar o corpo da filha. Sem saber que fora da opção dada à filha: "ou ela, ou eu", havia outras saídas, a mãe se tranquiliza porque as coisas voltaram para seu devido lugar. Todavia, Gina não aceita essas opções e parte para a saída radical: o suicídio. Ela "escolheu, cortar com aquela tesourinha, tique! O fio da vida no mesmo estilo oblíquo com que cortara os caules" (TELLES, 1998, p. 138).

Com esse deslocamento fatal de Gina, "Uma branca sombra pálida" traz para a história da Literatura Brasileira, uma narrativa que assinala o lugar da identidade homossexual como parte dos fantasmas da heterossexualidade. Isso é possível porque esse conto 
privilegia o olhar perturbado da identidade normatizadora, pois o local do excluído limita o "humano" com seu exterior constitutivo e assombra suas fronteiras com a persistente possibilidade de sua rearticulação (BUTLER, 2001, p. 161). Portanto, esteticamente, esse conto questiona o fascismo por trás da normatização heterossexual.

Além disso, os dois deslocamentos identitários dessa narrativa reforçam a visão fantasmagórica da identidade homossexual: o da filha de fugir da imposição materna, e o da mãe de fugir do fantasma da homoafetividade da filha. Tais deslocamentos opostos também estão presentes nas dualidades do conto: entre a pureza da flor branca e a luxúria da vermelha, entre a salvação da Páscoa e a desgraça do suicídio, entre o amor das duas jovens e a culpa do sexo homoafetivo. Nesse jogo de oposições, temos pistas do entrelaçamento das identidades sexuais, na quais as diferenças são ressaltadas como parte de um todo.

O questionamento da filha morta também mostra o quanto "Uma branca sombra pálida" atualiza o debate sobre a representação da homoafetividade feminina na ficção brasileira, ao enfatizar o desgaste do olhar tradicional e questionar a visão fascista da normatização heterossexual. Com essa opção ideológica, a posição da mãe é castradora e não dá uma 
chance para as ambiguidades sexuais da filha que apresenta uma identidade transgressora, quando explora papéis sexuais próprios de um sujeito ambíguo (TOURAINE, 2007, p. 67).

Ao mostrar diversos deslocamentos, esse conto questiona o quanto a identidade tradicional busca racionalmente explicações incoerentes para sua forma de homogeneizar as identidades sexuais. Com a ruptura da norma, Gina mostra que sua identificação foi superada com as normas patriarcais da mãe. Ao optar pelo suicídio, ela ressalta seu momento de pânico, pois apenas queria ser aceita pela mãe como ela era, pois buscava "desesperadamente um 'nós'" a que lhe desse a oportunidade de viver seu pertencimento sexual clandestino (BAUMAN, 2005, p. 30).

Portanto, como analisado neste trabalho, a representação da personagem homossexual de Lygia Fagundes Telles se desloca por espaços sociais e imagináveis para ressaltar os discursos que controlam o corpo da lésbica. As duas obras apresentam o deslocamento da identidade homossexual feminina como uma estratégia de desconstrução da norma vigente, ao debater a construção da identidade sexual como uma construção que atua através da reiteração de normas, ao mesmo tempo em que produz e desestabiliza o curso dessa reiteração (BUTLER, 2001, p. 163). 
Nesse caso, nos espaços fugidios, a identidade homossexual se projeta como um fantasma a assombrar a estabilidade da heterossexualidade. Sem ser aceita socialmente, a personagem lésbica precisa de um outro espaço todo seu. Assim, as duas obras, em contextos diferentes, apresentam os limites da aceitação da sexualidade fora da heterossexualidade e contextualizam a identidade de gênero como "um ponto de convergência entre conjuntos específicos de relações, cultural e historicamente convergentes" (BUTLER, 2003, p. 29), relativizando o padrão e a fixidez da identidade legitimadora.

Tanto em Ciranda de Pedra, como em "Uma branca sombra pálida", a homoafetividade é anunciada como um projeto identitário que está sempre sendo adiado, pois a norma e o padrão heterossexual é imposto. Letícia não consegue dar continuidade à sua conquista, pois Virgínia não gostou da experiência homoafetiva. No caso de Gina, a mãe não abre espaço para outra representação sexual que não seja a tradicional. Mesmo sem essa realização homoafetiva, os dois textos nos convidam a uma reflexão crítica e propõem um sofisticado jogo de desconstrução da identidade legitimadora. Isso só é visível por meio de uma leitura preocupada com as questões de poder que 
perpassam essa representação. Essa postura crítica é parte desse novo paradigma de se fazer crítica literária, valorizando a identidade homoerótica e as questões invisibilizadas pela tradição literária (BAILEY, 2004, p. 16).

Nesses dois casos, a castração e o preconceito são questionados como construtos sociais e deixam pistas do quanto a identidade heterossexual não pode ser vista como única, pois "a fragilidade e a condição eternamente provisória da identidade não podem mais ser ocultada" (BAUMAN, 2005, p. 22). Dessa forma, à proporção que a construção da identidade passa a ser aceita como algo provisório e variável, o corpo da mulher abandona a posição fixa de submissão sexual para se projetar de um lugar instável e provisório.

Diante do identificado no duplo deslocamento da personagem feminina homoerótica, nas análises aqui feitas, podemos afirmar que essas identidades são marcadas pela vontade de liberdade e pela necessidade de refúgio. Portanto, esse outro espaço, fora da família, pode ser visto como uma marca do imaginário ficcional de Lygia Fagundes Telles. Portanto, a não completude da personagem homossexual, que viaja e se refugia, pode ser vista como parte da incoerência social da normatização sexual. Essas 
personagens recusam identidades fixas e optam por fronteiras. Com isso, assumem a inconstância como uma marca de seus deslocamentos (LOURO, 2008, p. 21).

Na narrativa de Lygia Fagundes Telles, a transgressão sexual é também uma postura híbrida e faz parte dos questionamentos dos valores morais que se perpetuam no espaço da família burguesa, uma vez que, em Ciranda de Pedra, Virgínia rompe com as limitações sociais para atingir sua independência, deixando-se envolver pela sedução de uma mulher, e em "Uma branca sombra pálida", Gina opta por assombrar a normatização da mãe como uma terceira opção que estava fora de qualquer lugar.

Nos dois casos, identificamos a representação da identidade homoafetiva como parte de uma reflexão política de contestação do padrão e do fixo, abrindo o espaço da literatura para a luta política pelos direitos dos homossexuais (Louro, 2008, p. 32), pois rearticula legitimamente "corpos que pesam", "como formas de viver que contam como 'vida', como vidas que vale a pena proteger, como vidas que vale a pena salvar, como vidas que vale a pena prantear" (BUTLER, 2001, p. 170). 


\section{REFERÊNCIAS}

BAUMAN, Zygmunt. Identidade. Entrevista a Benedetto Vecchi. Tradução Carlos A. Medeiros. Rio de Janeiro: Jorge Zahar, 2005.

BAILEY, Cristina Ferreira-Pinto. "O desejo lesbiano no conto de escritoras brasileiras contemporâneas". In: Mulheres e Literatura. Rio de Janeiro: UFRJ, ano 08, v.1, 2004, p.1-17. Disponível em http://www.litcult.net/ revistamulheres vol8.php?id=79. Acessado em 20 de abril de 2014.

BUTLER, Judith. Problemas de gênero. Tradução de Renato Aguiar. Rio de Janeiro: Civilização Brasileira, 2003.

. "Corpos que pesam: sobre os limites discursivos do "sexo"”. In: Louro, Guacira. O corpo educado: pedagogias da sexualidade. Tradução de Thomaz Tadeu da Silva. 2ed. Belo Horizonte: Autêntica, 2001, p. 151-172.

LOURO, Guacira Lopes. Um corpo estranho. Belo Horizonte: Autêntica, 2008.

TELLES, Lygia Fagundes. Ciranda de pedra. 31a. ed. Rio de Janeiro: Rocco, 1998.

. A noite escura mais eu. 4ed. Rio de Janeiro: Rocco, 1998.

TOURAINE, Alain. $O$ mundo das mulheres. Tradução de Francisco Morás. Petrópolis: Vozes, 2007.

Carlos Magno Gomes é professor de Teoria Literária da Graduação e Pós-Graduação em Letras da UFS. Doutor em Literatura pela UnB (2004), com pós-doutorado em Estudos Literários, pela UFMG (2013). 